Received Date : 13-Oct-2015

Revised Date : 03-Aug-2016

Accepted Date : 04-Aug-2016

Article type : Review Article

\title{
Emerging roles of calcium-activated $K$ channels and TRPV4 channels in lung oedema and pulmonary circulatory collapse
}

Ulf Simonsen ${ }^{1}$, Christine Wandall-Frostholm ${ }^{1}$, Aida Oliván-Viguera ${ }^{2}$, Ralf Köhler ${ }^{2}$

1. Department of Biomedicine, Pulmonary and Cardiovascular Pharmacology, Aarhus

University, 8000 Aarhus C, Denmark

2. Translational Research Unit, University Hospital Miguel Servet and IACS/IIS, and the Aragonese Agency for Investigation and Development (ARAID), Zaragoza, Spain.

Corresponding author:

Ulf Simonsen

Department of Biomedicine

Aarhus University

DK-8000 Aarhus C

Phone: +4587167685 , fax: +4586128804

E-mail: us@biomed.au.dk

\begin{abstract}
It has been suggested that the transient receptor potential cation (TRP) channel subfamily V (vanilloid) type 4 (TRPV4) and intermediate-conductance calcium-activated potassium (KCa3.1) channels contribute to endothelium-dependent vasodilation. Here we summarize very recent evidence for a synergistic interplay of TRPV4 and $\mathrm{KCa} 3.1$ channels in lung

This article has been accepted for publication and undergone full peer review but has not been through the copyediting, typesetting, pagination and proofreading process, which may lead to differences between this version and the Version of Record. Please cite this article as doi: 10.1111/apha.12768

This article is protected by copyright. All rights reserved.
\end{abstract}


disease. Among the endothelial $\mathrm{Ca}^{2+}$-permeable TRPs, TRPV4 is best characterized and produces arterial dilation by stimulating $\mathrm{Ca}^{2+}$-dependent $\mathrm{NO}$ synthesis and endotheliumdependent hyperpolarization. Besides these roles, some TRP channels control endothelial/epithelial barrier functions and vascular integrity, while KCa3.1 channels provide the driving force required for $\mathrm{Cl}^{-}$and water transport in some cells and most secretory epithelia. The three conditions, increased pulmonary venous pressure caused by left heart disease, high inflation pressure, and chemically-induced lung injury may lead to activation of TRPV4 channels followed by $\mathrm{Ca}^{2+}$ influx leading to activation of $\mathrm{KCa} 3.1$ channels in endothelial cells ultimately leading to acute lung injury. We find that a deficiency in KCa3.1channels protects against TRPV4-induced pulmonary arterial relaxation, fluid extravasation, hemorrhage, pulmonary circulatory collapse, and cardiac arrest in vivo. These data identify KCa3.1 channels as crucial molecular components in downstream TRPV4signal transduction and as a potential target for the prevention of undesired fluid extravasation, vasodilatation, and pulmonary circulatory collapse.

Key words: pulmonary circulation, collapse, endothelium, lung oedema, KCa3.1, TRPV4

\section{Introduction}

Left heart disease and increased pulmonary venous pressures cause pulmonary oedema of cardiac origin. Non-cardiogenic acute lung injury and adult respiratory distress syndrome (ARDS) can also cause pulmonary oedema because of an increased permeability for salts, proteins, and water in the lung (Ranieri et al. 2012). In man, acute lung injury and ARDS are characterized by an acute onset of respiratory failure with bilateral infiltrates on chest $\mathrm{x}$-rays, the absence of left atrial hypertension (pulmonary artery wedge pressure $<18$ $\mathrm{mmHg}$ ), and pulmonary arterial oxygen pressure that in case of acute lung injury is less than 
$300 \mathrm{mmHg}$ and in case of ARDS less than $200 \mathrm{mmHg}$ (Ranieri et al. 2012). The 28 day mortality is approximately $25-30 \%$ of both acute lung injury and ARDS in man (Ware \& Matthay 2000). Among the events leading to acute lung injury and ARDS, an inflammation with infiltration of immune cells and leakage of protein-rich fluid into interstitium and alveoli are of major pathomechanistic importance. The resulting lung oedema produces a diffusion mismatch, and shunting of the blood in the lung, finally leading to respiratory failure. Despite the presence of inflammation, the effect of steroids on the conditions is limited to less need of use of vasopressors, more ventilator and shock free days, less skeletal muscle weakness, and short-term improvement in oxygenation. However, the steroid treatment does seemingly not reduce mortality (Steinberg et al. 2006). Although some studies with small numbers of patients have shown potential benefit of e.g. inhaled prostacyclin, epoprostenol, and nitric oxide (NO), there is no convincing evidence to date that any of these drugs saves lives in acute lung injury and ARDS (Duggal et al. 2015, Searcy et al. 2015). Therefore, there is a clear need for novel therapeutic strategies for these conditions as well as a more profound understanding of the underlying pathophysiological mechanisms.

The role of transient potential receptor channels vanilloid type 4 (TRPV4) channels in respiratory diseases has been reviewed recently (Goldenberg et al. 2015). Here we review new evidence for TRPV4 channels in endothelium-dependent vasodilatation in the pulmonary circulation and the role of these channels in lung oedema and pulmonary circulatory collapse. Finally, we review recent evidence showing that lung TRPV4 channels interact with countercurrent producing and membrane hyperpolarizing calcium-activated channels with intermediate conductance (KCa3.1) and that genetic deficit of these $\mathrm{K}$ channels in mice $\left(\mathrm{KCa} 3.1^{-/-}\right)$is protective against TRPV4-induced pulmonary circulatory collapse and oedema. 


\section{Role of endothelial TRPV4 channels and KCa3.1 in endothelium-dependent vasodilatation}

The TRPV4 channel is a remarkable non-selective cation channel with considerable calcium conductance $(\mathrm{PCa} / \mathrm{PNa} \approx 8)$ that is gated poly-modally by chemical factors such endogenous arachidonic acid (AA) and eicosanoids (Table 1), as well as by physical forces e.g. osmotic stress and membrane stretch (Figure 1, (Clapham 2003)). It is well established that TRPV4 is expressed in the endothelium of systemic and renal arteries (Chen et al. 2015a, Kohler et al. 2006, Watanabe et al. 2003), and is likely to mediate $\mathrm{Ca}^{2+}$ entry in the endothelium in response to AA-release stimulating signals (Qian et al. 2014) and to sudden increases in hemodynamic forces such as flow and shear stress as it occurs during reperfusion (Hartmannsgruber et al. 2007, Kohler et al. 2006) as well as to abnormally high intracapillary pressure (Hamanaka et al. 2007, Yin et al. 2008). In the lung, TRPV4 channels are expressed in the bronchial epithelium, capillary endothelium, and in smooth muscle of extra-alveolar arterioles (Alvarez et al. 2006, Fernandez-Fernandez et al. 2008). By patch clamp we recently provided evidence for functional TRPV4 channels in native mouse pulmonary arterial endothelial cells (Wandall-Frostholm et al. 2015) and mRNA-expression studies suggest the presence of TRPV4 in both, the endothelium and smooth muscle layer of rat large pulmonary arteries (Sukumaran et al. 2013). This is further supported by immunohistological proof of TRPV4 protein in both media and intima of pulmonary arteries in rats (Pankey et al. 2014). However, it remains to be elucidated, which humoral stimulus and/or chemical/physical forces that lead to activation of the TRPV4 channels in the pulmonary circulation. Indeed, mechanical stretch during respiration has been proposed to activate stretch-sensitive channels (Goldenberg et al. 2015), and TRPV4 is likely to act as such a mechanosensitive channel in the lung. 
In addition to mechanical stimulation, formation of epoxyeicosatrienoic acids (EETs) from their precursor AA has been suggested to activate TRPV4 channels (Vriens et al. 2004, Watanabe et al. 2003).Agonist-induced stimulation with acetylcholine also leads to TRPV4 activation and $\mathrm{Ca}^{2+}$ entry causing vasodilatation that is mediated by the two major endothelial vasodilator systems, the $\mathrm{Ca}^{2+}$-dependent endothelial nitric oxide synthase (eNOS) (Kohler $e t$ al. 2006) and the endothelium-derived hyperpolarization (EDH) pathway as concluded from studies in carotid and mesenteric arteries from mice and rats (Hartmannsgruber et al. 2007, Sonkusare et al. 2012, Sonkusare et al. 2014). Yet, there is no clear evidence that TRPV4 channels contribute to the physiologic regulation of systemic blood flow and pressure as concluded from the normal/low systemic blood pressure in TRPV4-deficient mice (Earley et al. 2009). Nonetheless, pharmacological activation of TRPV4 by systemic administration of

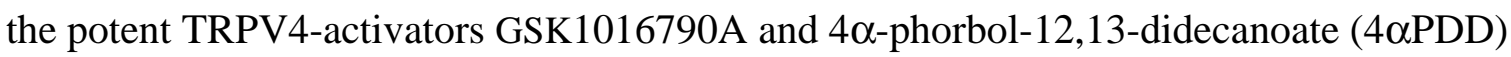
produces a strong drop in systemic blood pressure in mice, rats, and dogs (Pankey et al. 2014, Willette et al. 2008). In the pulmonary circulation activation of TRPV4 channels by GSK1016790A was initially suggested to lead to vasoconstriction (Willette et al. 2008). In the intact-chest rat model infusion of GSK1016790A only evoked constriction in the pulmonary circulation after treatment with the NO synthase inhibitor, N-nitro-L-arginine, while low doses of GSK1016790A in the absence of NO synthase inhibitor, caused small decreases in pulmonary arterial pressure (Pankey et al. 2014). In isolated constantly perfused mouse lungs, GSK1016790A increased pressure suggesting that it induced vasoconstriction (Ke et al. 2015). However, as previously pointed out by others a major limitation of these studies were that they were performed in perfused lungs without ventilation (Gollasch \& Kubler 2016). In isolated pulmonary arteries, blockade of TRPV4 channels inhibited 5hydroxytryptamine-induced contraction (Xia et al. 2013, Yang et al. 2012), and in murine pulmonary arteries without endothelium, GSK1016790A increased contractions induced by 
phenylephrine suggesting that smooth muscle TRPV4 channels were involved in the contraction (Wandall-Frostholm et al. 2015). In chronic hypoxic rats expression of TRPV4 channels is increased and contributes to the increased 5-hydroxytryptamine-induced contraction in the pulmonary arteries (Yang et al. 2012). Moreover, it has been suggested that TRPV4 channels may also contribute to acute hypoxic vasoconstriction in the lung (Morty \& Kuebler 2014), implying that these channels may play a role in the von Euler-Liljestrand mechanism, where the blood is redistributed by vasoconstriction from poorly to better ventilated lung areas. In addition to TRPV4 channels, TRPV2 channels have been proposed to contribute to acute hypoxic vasoconstriction (Yoo et al. 2012), and therefore, further studies are warranted to clarify the role of smooth muscle TRPV4 channels in the von EulerLiljestrand mechanism.

In addition to functional smooth muscle TRPV4 channels, TRPV4 channels in the endothelium play an important role in the pulmonary circulation (Figure 2). In rat pulmonary arteries contracted with phenylephrine, increasing concentrations of GSK1016790A caused endothelium-dependent relaxations (Sukumaran et al. 2013), and these relaxations were presumably mediated both by NO and activation of calcium-activated K channels (Sukumaran et al. 2013). In isolated pulmonary arteries from mice, GSK1016790A also caused endothelium-dependent relaxations that were sensitive to a selective blocker of TRPV4 channels, HC067047. Moreover, GSK1016790A relaxations were reduced by inhibition of NO synthase and by KCa3.1 deficiency in pulmonary arteries from $\mathrm{KCa}^{-1 /-}$ mice. The impairment of the GSK1016790A relaxations was more pronounced in more distal intrapulmonary arteries from $\mathrm{KCa} 3.1^{-/-}$mice (Wandall-Frostholm et al. 2015). These studies suggest that activation of TRPV4 channels in the proximal pulmonary arteries mainly leads to relaxations mediated by NO, while in distal smaller arteries, TRPV4 channel activation leads also to activation of the EDH pathway. This was also supported by our observations that 
inhibition of NO synthase inhibited only weakly the blood pressure lowering effects of infused GSK1016790A in the mouse pulmonary lung. In contrast, KCa3.1 channel deficiency in $\mathrm{KCa} 3.1^{-/-}$mice prevented this pressure drop (Wandall-Frostholm et al. 2015) suggesting a major role of $\mathrm{KCa} 3.1$-activation in here. Indeed, in patch-clamp studies in freshly isolated pulmonary arterial endothelial cells we found that GSK1016790A co-activated KCa3.1 and also to a minor extent small conductance calcium-activated $\mathrm{K}$ channels (KCa2) (WandallFrostholm et al. 2015). It has also been shown that TRPV4-induced endothelial $\mathrm{Ca}^{2+}$ events (sparklets) are capable of activating co-localized KCa3.1 in mesenteric resistance arteries (Sonkusare et al. 2012). Thus, from the cell biological perspective, our and previous findings prove functional synergism of the two channels.

The finding of a major role of $\mathrm{KCa} 3.1$ in endothelial vasodilator function in the pulmonary arteries is in line with previous findings in other vascular beds showing impaired EDH- and NO-type relaxations to acetylcholine in the cremaster microcirculation and in large carotid arteries of KCa3.1 ${ }^{-/-}$mice (Hasenau et al. 2011, Si et al. 2006, Wolfle et al. 2009).

As already indicated above, $\mathrm{KCa} 3.1$ is apparently co-expressed with the calcium/calmodulin-gated KCa2.3 subtype (a close phylogenetic relative with smaller conductance) in pulmonary arterial endothelium and the endothelium of systemic vessels (Brahler et al. 2009, Edwards et al. 1998, Kroigaard et al. 2012). The presence of the two channels is explained by the fact that they serve different physiological functions: in isolated mesenteric arteries $\mathrm{KCa} 2.3$ channels were suggested to exert a more tonic hyperpolarizing and vasodilating impact while the role of $\mathrm{KCa} 3.1$ channels is to help repolarizing the endothelium (Crane et al. 2003). Moreover, KCa3.1 channels are particularly responsive to acetylcholine-induced calcium-release from IP3-sensitive stores promoting subsequent calcium-entry through TRPV4 channels (Qian et al. 2014), and initialization of EDH-type dilatations in murine arteries. However, in isolated human and murine pulmonary arteries and 
bronchioles $\mathrm{KCa} 2.3$ channels seem to be more important than $\mathrm{KCa} 3.1$ for $\mathrm{EDH}$ dilations as concluded from the stronger inhibitory effect of the $\mathrm{KCa} 2$ blocking toxin apamin on relaxations produced by an unselective opener, NS309 of KCa3.1 and KCa2 channels (Kroigaard et al. 2012, Wandall-Frostholm et al. 2014). Also another blocker of KCa2 channels, UCL1618, inhibits strongly the relaxations following pharmacological opening of TRPV4 in mouse pulmonary arteries, although the contributions of $\mathrm{KCa} 2$ channels to current is small in pulmonary endothelial cells from wild type animals, but appreciable in pulmonary artery endothelial cells from KCa3.1-deficient mice (Wandall-Frostholm et al. 2015).

Therefore, the physiological role of activation of KCa2.3 by TRPV4 channel opening in the lung remains to be clarified.

\section{Role of TRPV4 in pulmonary vascular collapse and lung oedema}

There is emerging evidence suggesting that stretch activation of TRPV4 channels followed by pulmonary vascular pressure-mediated $\mathrm{Ca}^{2+}$ uptake is involved in acute lung injury (Figure 3). Alvarez and colleagues found that disruption of the lung and perivascular and alveolar liquid accumulation following stimulation with the TRPV4-activators, 4- $\alpha$ PDD and 14,15 EET, was reduced in mice deficient of TRPV4 channels, while this was not the case for lung injury induced by calcium overload that was evoked by thapsigargin-induced endoplasmic reticulum calcium depletion (Alvarez et al. 2006). Moreover, in isolated lungs, high intravascular pressure is associated with increased endothelial cell calcium and alveolar liquid accumulation, effects, which were not present in lungs from TRPV $4^{-/-}$mice and were blocked by inhibition of P450 epoxygenase or by blocking TRPV4 channels with ruthenium red (Jian et al. 2008, Yin et al. 2008). However, it is also worth mentioning that increases of cyclic GMP caused by either NO donors or by inhibition of phosphodiesterase type 5 with sildenafil were likewise capable of preventing oedema and the capillary endothelial calcium 
overload in lungs of rats with acute failure of the left ventricle after induction of a large myocardial infarction (Yin et al. 2008). Intriguingly, the novel potent TRPV4 blocker, GSK2193874, inhibited oedema in isolated lungs generated by high pulmonary venous pressure in mice and was also found to be efficient in preventing lung oedema in a murine myocardial infarction model (Thorneloe et al. 2012). These data from preclinical investigations suggest a role for TRPV4 channel activation and increased endothelial calcium in lungs exposed to sudden increases of high hydrostatic intravascular pressure, and that TRPV4 channel blockers may have efficacy in at least lung oedema with cardiac origin. Interestingly, in a rat model of chronic congestive heart failure (supracoronary aortic banding) impairment of pulmonary endothelium-dependent vasodilatation and endothelial cell calcium responses were observed in response to mechanical stress and agonist stimulation, and these alterations were associated with downregulation of TRPV4 channel expression (Kerem et al. 2010). The authors also found reduced NO formation and marked cytoskeletal reorganization in the endothelial cell layer (Kerem et al. 2010), suggesting that in chronic heart failure of the left ventricle, the pulmonary vasculature adapts by functional and morphological remodeling to increased pulmonary pressure.

Ventilation by use of a respirator can at least in certain conditions (e.g. high peak inflation pressure or by high end expiratory pressure) lead to lung injury in human subjects (Neto et al. 2015). In isolated mouse lungs exposed to either low or high peak inflation pressure, the pulmonary filtration coefficient $\left(\mathrm{K}_{\mathrm{f}}\right)$ was increased in the mouse lungs exposed to high peak inflation pressure, but this was not the case in lungs from TRPV4 ${ }^{-/-}$mice, and the effect of high inflation pressure was also blocked by ruthenium red (Hamanaka et al. 2007). The effect of high inflation pressure may, in addition to activation of TRPV4 channels in the epithelium and endothelium, also lead to activation of TRPV4 channels in macrophages, 
since instillation of macrophages from $\mathrm{TRPV}^{+/+}$mice markedly increased $\mathrm{K}_{\mathrm{f}}$ in isolated lungs from TRPV4 ${ }^{--}$mice (Hamanaka et al. 2010).

Chemical and acid exposure e.g. by aspiration of gastrointestinal content can produce non-cardiogenic acute lung injury and ARDS. In mice instillation of $\mathrm{HCl}$ or inhalation of chlorine were associated with infiltration of the lungs with macrophages and neutrophils and a worsening of the lung damage in TRPV $4^{+/+}$mice, while these effects were absent in lungs from TRPV4 ${ }^{-/-}$mice (Balakrishna et al. 2014). Administration of two selective TRPV4 channel inhibitors after exposure to $\mathrm{HCl}$ or chlorine, also reduced infiltration of macrophages and neutrophils, reduced the elevated levels of cytokines, and improved the histopathological score (Balakrishna et al. 2014). However, a recent study reported only a prophylactic effect of GSK2193874 against acid-induced acute lung injury and infiltration of neutrophils in murine lungs, while there was no effect of another TRPV4 blocker, HC067047 against lung injury (Yin et al. 2016). Still, the expression of TRPV4 channels in both macrophages and neutrophils opens the possibility/perspective that blockade of these channels may reduce tissue damage caused by e.g. lung infection and damaging chemical substances.

In summary, TRPV4 channels appear to be involved in acute lung injury caused by increased hydrostatic pressure due to left heart disease, high inflation pressure, and chemically induced lung injury. These preclinical studies clearly suggest that there could be a potential for use of TRPV4 channel blockers for treatment of patients with acute lung injury. The treatment may be safe as concluded from animal studies, in which TRPV4 channels blockers do not seem to possess obvious adverse cardiovascular effects. However, it remains to be clarified whether these blockers inhibit the Euler-Liljestrand mechanism as previously proposed (Morty \& Kuebler 2014), and hence the redistribution of blood from hypoxic to oxygenated areas in the lung which could be devastating due to even lower blood oxygen 
saturation levels in lung injury. Thus, pharmacological TRPV4 blockade in contrast to pharmacological TRPV4 activation appears to be safe, although this still needs to be proven experimentally.

\section{Protective role of genetic deficit of KCa3.1 against TRPV4-induced pulmonary circulatory collapse and oedema}

In normal physiological conditions osmotically-driven water transport across cell membranes is thought to be the principle mechanism of fluid transport. In the lung, it has been suggested that water channels, aquaporins, and especially aquaporin 4 and 5 are important for liquid clearance in the alveoles, while in lung microvascular endothelium aquaporin 1 is considered the main predominantly expressed water channel (Verkman 2007). However, mice deficient of either aquaporin 1 , 4, or 5 accumulate liquid in the lung to similar levels as control mice in response lung injury (Song et al. 2000). However, the slow rates of fluid transport support that aquaporins may add only marginally to transepithelial water transport in the lungs (Verkman 2007). In heart failure pressure-driven bulk fluid flow produces lung edema and pleural effusions (Berthiaume \& Matthay 2007, Verkman 2007), while in lung injury (ALI and ARDS) there is pulmonary permeability edema and it can be accompanied by (Lucas et al. 2009): (1) reduction of alveolar liquid clearance capacity, thought to be caused by an inhibition of the expression of crucial sodium transporters (ENac), the cyclic AMP-regulated cystic fibrosis transmembrane regulator chloride channel (CFTR), and the $\mathrm{Na}^{+} \mathrm{K}^{+}$-ATPase (Figure 3), (2) an endothelial/epithelial hyperpermeability, which to a large degree is cytokine induced, and (3) a disruption of the epithelial and endothelial barriers caused by increased apoptosis and necrosis. As mentioned above TRPV4 channels appear to play a role both in cardiac and lung jnjury-induced oedema, and the coupling of the TRPV4 activation to $\mathrm{KCa} 3.1$ channels seems to be important. 
To remind the reader, the $\mathrm{KCa} 3.1$ channel is a calcium-activated $\mathrm{K}$ channel of intermediate-conductance (20-40 pS) that is activated by calcium-binding to calmodulin that is constitutively bound to the cytosolic c-terminus and acts as the $\mathrm{Ca}^{2+}$ sensing beta-subunit of the channels $\left(\mathrm{EC}_{50}, 250-500 \mathrm{nM}\right) . \mathrm{K}_{\mathrm{V}}$ channels and the $\mathrm{KCa} 1.1$ channels have a voltage sensor that causes channel inactivation at negative membrane potentials, but this is not the case for the KCa3.1 channel which lacks a voltage sensor. This enables the channel, unlike $\mathrm{K}_{\mathrm{V}}$ channels, to produce solid and lasting hyperpolarization up to the $\mathrm{K}$ channel equilibrium potential of around $-89 \mathrm{mV}$. KCa3.1 is found in several white blood cell linages, in erythrocyte (Gardos channel) and in most secretory epithelia where KCa3.1 channels play important roles in the control of fluid movements because $\mathrm{K}$ efflux through the channel and concomitant hyperpolarization provide the electrical driving force for chloride efflux through apical $\mathrm{Cl}^{-}$channels (occurring at potentials more negative than the chloride equilibrium potential of around $-30-50 \mathrm{mV}$ in epithelia) and concomitant water movements. This could be an important mechanism in airway epithelia and other epithelia, in which presumably basolateral located KCa3.1 channels functionally interplays with the apical CFTR chloride channel, and $\mathrm{Ca}^{2+}$-activated $\mathrm{Cl}^{-}$channels (CaCC encoded by the TMEM16A gene) to enable transepithelial chloride and water secretion in response to stimuli triggering cAMP-elevations and increase of intracellular $\mathrm{Ca}^{2+}$ (Bertuccio et al. 2014, Mall et al. 2003, Vazquez et al. 2001). Thereby, KCa3.1 channels could pivotally contribute to the control of mucus production and its stickiness in the airways and to transepithelial chloride and water transport as previously described for gastric and intestinal epithelia as well as exocrine salivary glands (Catalan et al. 2014). Therefore, KCa3.1 channel blockade, deficiency or downregulation could be strategies to prevent excessive transepithelial fluid transport caused by pathologically high pressures in the pulmonary arterial and venous circulation. 
Phenotyping of KCa3.1 gave important information about the in-vivo roles of the channel. Concerning erythrocytes, in which $\mathrm{KCa} 3.1$ is known to be involved in the control of cell volume, we found that KCa3.1-deficiency produced subtle macrocytosis (a sign of mild overhydration and fragility) and progressive splenomegaly as the perhaps an anatomical "visible" phenotype (Grgic et al. 2009). Considering the large body of literature regarding the role of $\mathrm{T}$ cell $\mathrm{KCa} 3.1$ in the immune response, it is interesting to realize that the $\mathrm{KCa} 3.1^{-/}$ mice are generally not immune suppressed. With respect to the systemic circulation, deficiency of KCa3.1 channels leads to a significant increase in pulse pressure and a mild elevation of systolic blood pressure exclusively during physical activity with no change in diastolic pressure (Si et al. 2006). Regarding alterations in the pulmonary system, we have studied a series of lung parameters in $\mathrm{KCa} .1^{-/-}$mice and wild type mice. By use of a flexiVent system (SCIREQ Inc, Montreal, Qc, Canada) we fitted dynamic pressure-volume loops to a single compartment model to calculate system resistance and elastance, and by use of the forced oscillation technique data were fit to the constant phase model to calculate central airway resistance and tissue elastance and tissue damping as previously described (McGovern et al. 2013, Phillips et al. 2012). Tracheal instillation of bleomycin markedly increased system and tissue elastance, reflecting increased stiffness in these functional lung fibrosis parameters both in wild type and $\mathrm{KCa}_{3} 1^{-/-}$mice (Figure 4), and the changes in other respiratory parameters also changed similarly in wild type and $\mathrm{KCa} 3.1^{-/-}$mice suggesting that these patophysiological changes were independent of the KCa3.1 channel. Considering ventricular and pulmonary pressure, the right ventricular pressure is unaltered in $\mathrm{KCa} 3.1^{-/-}$ mice (Wandall-Frostholm et al. 2015). Moreover, the combination of complete lack of $\mathrm{KCa} 3.1$ and reduction of $\mathrm{KCa} 2.3$ expression in $\mathrm{KCa} 3.1^{-/-} / \mathrm{KCa} 2.3^{\mathrm{T} / \mathrm{T}}$ Dox mice (Brahler et al. 2009) did not alter pulmonary hypertension although there were structural changes of the heart (increased right ventricular wall thickness) and larger pulmonary arteriole lumen 
diameters in this strain compared to wild-type mice (Wandall-Frostholm et al. 2014), which are presumably caused by the manipulation of the $\mathrm{KCa} 2.3$ expression levels rather than by KCa3.1-deficiency.

Importantly, we found that following infusion of the TRPV4 opener GSK106790A, $\mathrm{KCa} 3.1^{-/-}$mice were protected against lung hemorrhage and lung oedema as concluded from histological examination and measurements of perivascular cuffing and widening of extravascular spaces in the lung (Wandall-Frostholm et al. 2015). Moreover, infusion of GSK106790A caused vascular collapse and death in wild type mice, but not in $\mathrm{KCa} 3.1^{-/-}$ mice. Recent findings further support this concept by showing that in the isolated rat lung, infusion of the endogenous TRPV4-activators, EETs increase the filtration coefficient, an effect prevented by blocking KCa3.1 channels with TRAM-34 (Lin et al. 2015). This suggests that activation of KCa3.1 channels plays a pivotal role in fluid extravasation in the lung induced by TRPV4 activation as outlined in Figure 3. Thus, we speculate that the three conditions, 1) increased pulmonary venous pressure caused by left heart disease, 2) high inflation pressure, and 3) chemically-induced lung injury activate calcium influx through TRPV4 in the lung endothelium/epithelium that in turn triggers opening of KCa3.1 channels. The concomitant hyperpolarization generates a positive feed-back loop on calcium influx through TRPV4 channels while at the same time the hyperpolarization provides a sufficiently negative membrane potential to push also negatively charged chloride through chloride channels out of the cells. These movements of $\mathrm{K}$ and $\mathrm{Cl}$ force water to follow and to accumulate in the interstitium and alveoli. There are several pieces of additional evidence supporting this concept. 1) When comparing the ratios of dry weight and wet weight as a measure of water content between genotypes, we found that the ratios were higher (indicative of liquid accumulation) in wild type lungs exposed to the TRPV4 channel opener, GSK106790A, than in lungs from KCa3.1 $1^{-/-}$mice (Figure 5). 2) Liquid accumulation 
measured as cuffs around extra-alveolar vessels or widening of extracellular space in histological sections were increased in response to GSK106790A in wild type mice, but these effects were markedly reduced in $\mathrm{KCa}_{3} 1^{-/-}$mice (Wandall-Frostholm et al. 2015). 3)We found that TRAM-34 was able to prevent TRPV4-induced cell swelling and to reduce membrane blebs in endothelial cell cultures, again suggesting that $\mathrm{K}$ efflux through $\mathrm{KCa} 3.1$ channels plays a role in endothelial cell integrity and barrier function (Figure 3, (WandallFrostholm et al. 2015).

ARDS is characterized by leakage of protein-rich oedema fluid, and this is mimicked by activation of the TRPV4 channel and is absent in TRPV $4^{-/-}$mice (Alvarez et al. 2006). In the $\mathrm{KCa} 3.1^{-/-}$mice, we investigated protein extravasation by using Evans blue and found a massive accumulation of Evans blue in the lungs from both wild type and $\mathrm{KCa} 3.1^{-/-}$mice. There was no obvious difference between the genotypes (Wandall-Frostholm et al. 2015). These findings suggest that the $\mathrm{KCa} 3.1$ channel plays a pivotal role at least for interstitial fluid accumulation and vascular collapse leading to death following pharmacological TRPV4 channel activation. As mentioned earlier, TRPV4 channel blockade prevents infiltration with neutrophils and macrophages in lung injury in mice (Yin et al. 2016), but at present it is unclear whether infiltration of immune cells in the lung is affected by $\mathrm{KCa} 3.1$ channel deficiency.

In summary, the findings that TRPV4 channels play a role in both cardiac and noncardiac lung oedema suggest that, TRPV4 channel activation, in addition to perhaps reduced alveolar liquid clearance by ENac, CFTR, and $\mathrm{Na}^{+} \mathrm{K}^{+}$-ATPase, mediate rapid liquid extravasation by coupling to the $\mathrm{KCa} 3.1$ channels and likely to calcium-activated chloride channels $(\mathrm{CaCC})$ to produce potassium and chloride outflow, and concomitant fluid movement into the interstitium and alveoli (Figure 3). 


\section{Do KCa3.1 blockers have therapeutic utility against pulmonary circulatory collapse and}

oedema?

Based on our studies in mice $\mathrm{KCa} 3.1^{-/-}$mice (Wandall-Frostholm et al. 2015), blockade of $\mathrm{KCa} 3.1$ could be a strategy to prevent excessive transepithelial fluid transport caused by pathologically high pressures in the pulmonary arterial and venous circulation. In such a scenario, selective blockers of KCa3.1 such as TRAM-34, Senicapoc (ICA-17043), cyclohexadienes (Mauler et al. 2004) or the novel negative-gating modulator, the dibenzoate ester, RA-2 (Olivan-Viguera et al. 2015) may prevent lung oedema formation when applied from the bronchial side to minimize potential systemic effects on blood pressure. While this is hypothetical for the lung, there are studies on the brain that suggest such utilities for prevention of oedema: A cyclohexadiene compound efficiently reduces brain oedema in a rat acute subdural haematoma model (Mauler et al. 2004). TRAM-34 has been shown to block blood-brain-barrier $\mathrm{KCa} 3.1$ and thereby sodium-uptake to the affected brain areas after ischemic stroke (Chen et al. 2015b). Therefore, a series of preclinical studies have to be conducted to explore the possibility of using KCa3.1 blockers for treatment of pulmonary oedema and vascular collapse. Moreover, it is required to address whether combined blockade of $\mathrm{KCa} 2$ and $\mathrm{KCa} 3.1$ channels provide additional beneficial effect, and whether blockade of KCa3.1 channels provide similar or better outcome compared to TRPV4 channel blockade in the treatment of pulmonary oedema and collapse.

Drugs for treating pulmonary oedema of cardiac origin (acute heart failure) are diuretics, positive inotropic drugs (e.g. levosimendan, dobutamine, dopamine), and depending on the systemic blood pressure also vasodilators according to the guidelines of the European Society of Cardiology (McMurray et al. 2012). In keeping with the potential roles of TRPV4 channels in lung oedema with cardiac origin, it is thinkable that specific blockade of these channels may resolve or help to resolve the condition. Concerning KCa3.1 channels 
it remains to be clarified whether they represent potential drug targets in pulmonary oedema of cardiac origin.

Treatment with $\mathrm{KCa} 3.1$ blockers affects hematological parameters. In mice, treatment with TRAM-34 (120 mg/kg/day, i.p.) over 4 weeks produced mild splenomegaly (142\% of control) and hepatomegaly (+153\%) and improved erythrocyte hemoglobin content and hematocrit, although the treatment caused a decrease in erythrocyte count (-8\%) and an increase in reticulocyte count $(+66 \%)$. The treatment did not cause erythrocyte macrocytosis but led to a significant increase in red blood cell distribution width (Köhler, unpublished observations), suggesting alterations in erythrocyte volume regulation in mice. Another KCa3.1-blocker, Senicapoc, advanced into clinical trials for sickle cell disease and was found to increase hemoglobin levels and reduce hemolysis although it failed to reach the primary endpoint, a reduction in painful vaso-oclusive crisis. Yet, a 12-week treatment with the compound was found to be safe in humans at a peroral dosage of $10 \mathrm{mg} /$ day (Ataga et al. 2008). Although this drug at first sight appears clinically safe, additional safety studies will be required before repurposing this drug or using other drug candidates for treating patients with the above-mentioned lung conditions.

Small molecule activators of the $\mathrm{KCa} 2$ and $\mathrm{KCa} 3.1$ channels such as DC-EBIO, NS309, and the more KCa3.1-selective SKA-121 may have therapeutic potential in cystic fibrosis, chronic obstructive pulmonary disease (COPD), and in other diseases characterized by impaired secretory activity (Christophersen \& Wulff 2015, Coleman et al. 2014, Kroigaard et al. 2012, Syme et al. 2000). However, with respect to the lung, there are some concerns regarding the utility of $\mathrm{KCa} 3.1$ activators because they may bear the risk to promote oedema formation by stimulating transepithelial $\mathrm{Cl}$ - secretion, fluid extravasation, and alveolar flooding. 


\section{Acknowledgement}

Ulf Simonsen is supported by the Danish Heart Foundation and is part of MEMBRANES,

Aarhus University. I would like to thank the Stiftelsen Nordisk Fysiologi, SNF for generous support for the AP Symposium on “Endothelium-dependent hyperpolarizations 2015”.

\section{Conflict of interest}

None

\section{References}

Alvarez, D. F., King, J. A., Weber, D., Addison, E., Liedtke, W. \& Townsley, M. I. 2006. Transient receptor potential vanilloid 4-mediated disruption of the alveolar septal barrier: a novel mechanism of acute lung injury. Circ Res 99, 988-995.

Ataga, K. I., Smith, W. R., De Castro, L. M., Swerdlow, P., Saunthararajah, Y., Castro, O., Vichinsky, E., Kutlar, A., Orringer, E. P., Rigdon, G. C. \& Stocker, J. W. 2008. Efficacy and safety of the Gardos channel blocker, senicapoc (ICA-17043), in patients with sickle cell anemia. Blood 111, 3991-3997.

Balakrishna, S., Song, W., Achanta, S., Doran, S. F., Liu, B., Kaelberer, M. M., Yu, Z., Sui, A., Cheung, M., Leishman, E., Eidam, H. S., Ye, G., Willette, R. N., Thorneloe, K. S., Bradshaw, H. B., Matalon, S. et al. 2014. TRPV4 inhibition counteracts edema and inflammation and improves pulmonary function and oxygen saturation in chemically induced acute lung injury. Am J Physiol Lung Cell Mol Physiol 307, L158-L172.

Berthiaume, Y. \& Matthay, M. A. 2007. Alveolar edema fluid clearance and acute lung injury. Respir Physiol Neurobiol 159, 350-359.

Bertuccio, C. A., Lee, S. L., Wu, G., Butterworth, M. B., Hamilton, K. L. \& Devor, D. C. 2014. Anterograde trafficking of KCa3.1 in polarized epithelia is Rab1- and Rab8-dependent and recycling endosome-independent. PLoS One 9, e92013.

Brahler, S., Kaistha, A., Schmidt, V. J., Wolfle, S. E., Busch, C., Kaistha, B. P., Kacik, M., Hasenau, A. L., Grgic, I., Si, H., Bond, C. T., Adelman, J. P., Wulff, H., de, W. C., Hoyer, J. \& Kohler, R. 2009. Genetic deficit of SK3 and IK1 channels disrupts the endothelium-derived hyperpolarizing factor vasodilator pathway and causes hypertension. Circulation 119, 2323-2332.

Catalan, M. A., Pena-Munzenmayer, G. \& Melvin, J. E. 2014. Ca(2)(+)-dependent K(+) channels in exocrine salivary glands. Cell Calcium 55, 362-368.

Chen, L., Kassmann, M., Sendeski, M., Tsvetkov, D., Marko, L., Michalick, L., Riehle, M., Liedtke, W. B., Kuebler, W. M., Harteneck, C., Tepel, M., Patzak, A. \& Gollasch, M. 2015a. Functional transient receptor potential vanilloid 1 and transient receptor potential vanilloid 4 channels along different segments of the renal vasculature. Acta Physiol (Oxf) 213, 481-491.

Chen, Y. J., Wallace, B. K., Yuen, N., Jenkins, D. P., Wulff, H. \& O'Donnell, M. E. 2015b. Blood-

This article is protected by copyright. All rights reserved. 
brain barrier KCa3.1 channels: evidence for a role in brain Na uptake and edema in ischemic stroke. Stroke 46, 237-244.

Christophersen, P. \& Wulff, H. 2015. Pharmacological gating modulation of small- and intermediateconductance $\mathrm{Ca}(2+)$-activated $\mathrm{K}(+)$ channels (KCa2.x and KCa3.1). Channels (Austin ) 9, 336343.

Clapham, D. E. 2003. TRP channels as cellular sensors. Nature 426, 517-524.

Coleman, N., Brown, B. M., Olivan-Viguera, A., Singh, V., Olmstead, M. M., Valero, M. S., Kohler, R. \& Wulff, H. 2014. New positive Ca2+-activated K+ channel gating modulators with selectivity for KCa3.1. Mol Pharmacol 86, 342-357.

Crane, G. J., Gallagher, N., Dora, K. A. \& Garland, C. J. 2003. Small- and intermediate-conductance calcium-activated $\mathrm{K}+$ channels provide different facets of endothelium-dependent hyperpolarization in rat mesenteric artery. J Physiol 553, 183-189.

Duggal, A., Ganapathy, A., Ratnapalan, M. \& Adhikari, N. K. 2015. Pharmacological treatments for acute respiratory distress syndrome: systematic review. Minerva Anestesiol 81, 567-588.

Earley, S., Pauyo, T., Drapp, R., Tavares, M. J., Liedtke, W. \& Brayden, J. E. 2009. TRPV4dependent dilation of peripheral resistance arteries influences arterial pressure. Am J Physiol Heart Circ Physiol 297, H1096-H1102.

Edwards, G., Dora, K. A., Gardener, M. J., Garland, C. J. \& Weston, A. H. 1998. K+ is an endothelium-derived hyperpolarizing factor in rat arteries. Nature 396, 269-272.

Fernandez-Fernandez, J. M., Andrade, Y. N., Arniges, M., Fernandes, J., Plata, C., Rubio-Moscardo, F., Vazquez, E. \& Valverde, M. A. 2008. Functional coupling of TRPV4 cationic channel and large conductance, calcium-dependent potassium channel in human bronchial epithelial cell lines. Pflugers Arch 457, 149-159.

Goldenberg, N. M., Ravindran, K. \& Kuebler, W. M. 2015. TRPV4: physiological role and therapeutic potential in respiratory diseases. Naunyn Schmiedebergs Arch Pharmacol 388, 421436.

Gollasch, M. \& Kubler, W. M. 2016. Re: Sun-Kui Ke et al. TRiPping over vasotonus regulation in the lung. Respir Physiol Neurobiol 227, 71-72.

Grgic, I., Kaistha, B. P., Paschen, S., Kaistha, A., Busch, C., Si, H., Kohler, K., Elsasser, H. P., Hoyer, J. \& Kohler, R. 2009. Disruption of the Gardos channel (KCa3.1) in mice causes subtle erythrocyte macrocytosis and progressive splenomegaly. Pflugers Arch 458, 291-302.

Hamanaka, K., Jian, M. Y., Townsley, M. I., King, J. A., Liedtke, W., Weber, D. S., Eyal, F. G., Clapp, M. M. \& Parker, J. C. 2010. TRPV4 channels augment macrophage activation and ventilator-induced lung injury. Am J Physiol Lung Cell Mol Physiol 299, L353-L362.

Hamanaka, K., Jian, M. Y., Weber, D. S., Alvarez, D. F., Townsley, M. I., Al-Mehdi, A. B., King, J. A., Liedtke, W. \& Parker, J. C. 2007. TRPV4 initiates the acute calcium-dependent permeability increase during ventilator-induced lung injury in isolated mouse lungs. Am J Physiol Lung Cell Mol Physiol 293, L923-L932.

Hartmannsgruber, V., Heyken, W. T., Kacik, M., Kaistha, A., Grgic, I., Harteneck, C., Liedtke, W., Hoyer, J. \& Kohler, R. 2007. Arterial response to shear stress critically depends on endothelial TRPV4 expression. PLoS One 2, e827.

This article is protected by copyright. All rights reserved. 
Hasenau, A. L., Nielsen, G., Morisseau, C., Hammock, B. D., Wulff, H. \& Kohler, R. 2011. Improvement of endothelium-dependent vasodilations by SKA-31 and SKA-20, activators of small- and intermediate-conductance Ca2+-activated K+-channels. Acta Physiol (Oxf) 203, 117 126.

Jian, M. Y., King, J. A., Al-Mehdi, A. B., Liedtke, W. \& Townsley, M. I. 2008. High vascular pressure-induced lung injury requires P450 epoxygenase-dependent activation of TRPV4. Am J Respir Cell Mol Biol 38, 386-392.

Ke, S. K., Chen, L., Duan, H. B. \& Tu, Y. R. 2015. Opposing actions of TRPV4 channel activation in the lung vasculature. Respir Physiol Neurobiol 219, 43-50.

Kerem, A., Yin, J., Kaestle, S. M., Hoffmann, J., Schoene, A. M., Singh, B., Kuppe, H., Borst, M. M. \& Kuebler, W. M. 2010. Lung endothelial dysfunction in congestive heart failure: role of impaired $\mathrm{Ca} 2+$ signaling and cytoskeletal reorganization. Circ Res 106, 1103-1116.

Kohler, R., Heyken, W. T., Heinau, P., Schubert, R., Si, H., Kacik, M., Busch, C., Grgic, I., Maier, T. \& Hoyer, J. 2006. Evidence for a functional role of endothelial transient receptor potential V4 in shear stress-induced vasodilatation. Arterioscler Thromb Vasc Biol 26, 1495-1502.

Kroigaard, C., Dalsgaard, T., Nielsen, G., Laursen, B. E., Pilegaard, H., Kohler, R. \& Simonsen, U. 2012. Activation of endothelial and epithelial $\mathrm{K}(\mathrm{Ca}) 2.3$ calcium-activated potassium channels by NS309 relaxes human small pulmonary arteries and bronchioles. Br J Pharmacol 167, 37-47.

Lin, M. T., Jian, M. Y., Taylor, M. S., Cioffi, D. L., Yap, F. C., Liedtke, W. \& Townsley, M. I. 2015. Functional coupling of TRPV4, IK, and SK channels contributes to $\mathrm{Ca}(2+)$-dependent endothelial injury in rodent lung. Pulm Circ 5, 279-290.

Lucas, R., Verin, A. D., Black, S. M. \& Catravas, J. D. 2009. Regulators of endothelial and epithelial barrier integrity and function in acute lung injury. Biochem Pharmacol 77, 1763-1772.

Mall, M., Gonska, T., Thomas, J., Schreiber, R., Seydewitz, H. H., Kuehr, J., Brandis, M. \& Kunzelmann, K. 2003. Modulation of Ca2+-activated Cl- secretion by basolateral $\mathrm{K}+$ channels in human normal and cystic fibrosis airway epithelia. Pediatr Res 53, 608-618.

Mauler, F., Hinz, V., Horvath, E., Schuhmacher, J., Hofmann, H. A., Wirtz, S., Hahn, M. G. \& Urbahns, K. 2004. Selective intermediate-/small-conductance calcium-activated potassium channel (KCNN4) blockers are potent and effective therapeutics in experimental brain oedema and traumatic brain injury caused by acute subdural haematoma. Eur J Neurosci 20, 1761-1768.

McGovern, T. K., Robichaud, A., Fereydoonzad, L., Schuessler, T. F. \& Martin, J. G. 2013. Evaluation of respiratory system mechanics in mice using the forced oscillation technique. $J$ Vis Exp, e50172.

McMurray, J. J., Adamopoulos, S., Anker, S. D., Auricchio, A., Bohm, M., Dickstein, K., Falk, V., Filippatos, G., Fonseca, C., Gomez-Sanchez, M. A., Jaarsma, T., Kober, L., Lip, G. Y., Maggioni, A. P., Parkhomenko, A., Pieske, B. M. et al. 2012. ESC Guidelines for the diagnosis and treatment of acute and chronic heart failure 2012: The Task Force for the Diagnosis and Treatment of Acute and Chronic Heart Failure 2012 of the European Society of Cardiology. Developed in collaboration with the Heart Failure Association (HFA) of the ESC. Eur Heart J 33, 1787-1847.

Morty, R. E. \& Kuebler, W. M. 2014. TRPV4: an exciting new target to promote alveolocapillary barrier function. Am J Physiol Lung Cell Mol Physiol 307, L817-L821.

Neto, A. S., Simonis, F. D., Barbas, C. S., Biehl, M., Determann, R. M., Elmer, J., Friedman, G.,

This article is protected by copyright. All rights reserved. 
Gajic, O., Goldstein, J. N., Linko, R., Pinheiro de, O. R., Sundar, S., Talmor, D., Wolthuis, E. K., Gama de, A. M., Pelosi, P. et al. 2015. Lung-Protective Ventilation With Low Tidal Volumes and the Occurrence of Pulmonary Complications in Patients Without Acute Respiratory Distress Syndrome: A Systematic Review and Individual Patient Data Analysis. Crit Care Med 43, 2155 2163.

Olivan-Viguera, A., Valero, M. S., Coleman, N., Brown, B. M., Laria, C., Murillo, M. D., Galvez, J. A., Diaz-de-Villegas, M. D., Wulff, H., Badorrey, R. \& Kohler, R. 2015. A novel pan-negativegating modulator of $\mathrm{KCa} 2 / 3$ channels, fluoro-di-benzoate, RA-2, inhibits endothelium-derived hyperpolarization-type relaxation in coronary artery and produces bradycardia in vivo. $\mathrm{Mol}$ Pharmacol 87, 338-348.

Pankey, E. A., Zsombok, A., Lasker, G. F. \& Kadowitz, P. J. 2014. Analysis of responses to the TRPV4 agonist GSK1016790A in the pulmonary vascular bed of the intact-chest rat. Am J Physiol Heart Circ Physiol 306, H33-H40.

Phillips, J. E., Peng, R., Burns, L., Harris, P., Garrido, R., Tyagi, G., Fine, J. S. \& Stevenson, C. S. 2012. Bleomycin induced lung fibrosis increases work of breathing in the mouse. Pulm Pharmacol Ther 25, 281-285.

Qian, X., Francis, M., Kohler, R., Solodushko, V., Lin, M. \& Taylor, M. S. 2014. Positive feedback regulation of agonist-stimulated endothelial $\mathrm{Ca} 2+$ dynamics by $\mathrm{KCa} 3.1$ channels in mouse mesenteric arteries. Arterioscler Thromb Vasc Biol 34, 127-135.

Ranieri, V. M., Rubenfeld, G. D., Thompson, B. T., Ferguson, N. D., Caldwell, E., Fan, E., Camporota, L. \& Slutsky, A. S. 2012. Acute respiratory distress syndrome: the Berlin Definition. JAMA 307, 2526-2533.

Searcy, R. J., Morales, J. R., Ferreira, J. A. \& Johnson, D. W. 2015. The role of inhaled prostacyclin in treating acute respiratory distress syndrome. Ther Adv Respir Dis 9, 302-312.

Si, H., Heyken, W. T., Wolfle, S. E., Tysiac, M., Schubert, R., Grgic, I., Vilianovich, L., Giebing, G., Maier, T., Gross, V., Bader, M., de, W. C., Hoyer, J. \& Kohler, R. 2006. Impaired endotheliumderived hyperpolarizing factor-mediated dilations and increased blood pressure in mice deficient of the intermediate-conductance Ca2+-activated K+ channel. Circ Res 99, 537-544.

Song, Y., Fukuda, N., Bai, C., Ma, T., Matthay, M. A. \& Verkman, A. S. 2000. Role of aquaporins in alveolar fluid clearance in neonatal and adult lung, and in oedema formation following acute lung injury: studies in transgenic aquaporin null mice. J Physiol 525 Pt 3, 771-779.

Sonkusare, S. K., Bonev, A. D., Ledoux, J., Liedtke, W., Kotlikoff, M. I., Heppner, T. J., HillEubanks, D. C. \& Nelson, M. T. 2012. Elementary Ca2+ signals through endothelial TRPV4 channels regulate vascular function. Science 336, 597-601.

Sonkusare, S. K., Dalsgaard, T., Bonev, A. D., Hill-Eubanks, D. C., Kotlikoff, M. I., Scott, J. D., Santana, L. F. \& Nelson, M. T. 2014. AKAP150-dependent cooperative TRPV4 channel gating is central to endothelium-dependent vasodilation and is disrupted in hypertension. Sci Signal 7, ra66.

Steinberg, K. P., Hudson, L. D., Goodman, R. B., Hough, C. L., Lanken, P. N., Hyzy, R., Thompson, B. T. \& Ancukiewicz, M. 2006. Efficacy and safety of corticosteroids for persistent acute respiratory distress syndrome. $N$ Engl J Med 354, 1671-1684.

Sukumaran, S. V., Singh, T. U., Parida, S., Narasimha, R. C., Thangamalai, R., Kandasamy, K., Singh, V. \& Mishra, S. K. 2013. TRPV4 channel activation leads to endothelium-dependent relaxation mediated by nitric oxide and endothelium-derived hyperpolarizing factor in rat

This article is protected by copyright. All rights reserved. 
pulmonary artery. Pharmacol Res 78, 18-27.

Syme, C. A., Gerlach, A. C., Singh, A. K. \& Devor, D. C. 2000. Pharmacological activation of cloned intermediate- and small-conductance $\mathrm{Ca}(2+)$-activated $\mathrm{K}(+)$ channels. Am J Physiol Cell Physiol 278, C570-C581.

Thorneloe, K. S., Cheung, M., Bao, W., Alsaid, H., Lenhard, S., Jian, M. Y., Costell, M., ManiscalcoHauk, K., Krawiec, J. A., Olzinski, A., Gordon, E., Lozinskaya, I., Elefante, L., Qin, P., Matasic, D. S., James, C. et al. 2012. An orally active TRPV4 channel blocker prevents and resolves pulmonary edema induced by heart failure. Sci Transl Med 4, 159ra148.

Vazquez, E., Nobles, M. \& Valverde, M. A. 2001. Defective regulatory volume decrease in human cystic fibrosis tracheal cells because of altered regulation of intermediate conductance $\mathrm{Ca} 2+-$ dependent potassium channels. Proc Natl Acad Sci U S A 98, 5329-5334.

Verkman, A. S. 2007. Role of aquaporins in lung liquid physiology. Respir Physiol Neurobiol 159, 324-330.

Vriens, J., Watanabe, H., Janssens, A., Droogmans, G., Voets, T. \& Nilius, B. 2004. Cell swelling, heat, and chemical agonists use distinct pathways for the activation of the cation channel TRPV4. Proc Natl Acad Sci U S A 101, 396-401.

Wandall-Frostholm, C., Dalsgaard, T., Bajoriunas, V., Olivan-Viguera, A., Sadda, V., Beck, L., Mogensen, S., Stankevicius, E., Simonsen, U. \& Kohler, R. 2015. Genetic deficit of K 3.1 channels protects against pulmonary circulatory collapse induced by TRPV4 channel activation. $\mathrm{Br}$ $J$ Pharmacol 172, 4493-4505.

Wandall-Frostholm, C., Skaarup, L. M., Sadda, V., Nielsen, G., Hedegaard, E. R., Mogensen, S., Kohler, R. \& Simonsen, U. 2014. Pulmonary hypertension in wild type mice and animals with genetic deficit in KCa2.3 and KCa3.1 channels. PLoS One 9, e97687.

Ware, L. B. \& Matthay, M. A. 2000. The acute respiratory distress syndrome. N Engl J Med 342, 1334-1349.

Watanabe, H., Vriens, J., Prenen, J., Droogmans, G., Voets, T. \& Nilius, B. 2003. Anandamide and arachidonic acid use epoxyeicosatrienoic acids to activate TRPV4 channels. Nature 424, 434-438.

Willette, R. N., Bao, W., Nerurkar, S., Yue, T. L., Doe, C. P., Stankus, G., Turner, G. H., Ju, H., Thomas, H., Fishman, C. E., Sulpizio, A., Behm, D. J., Hoffman, S., Lin, Z., Lozinskaya, I., Casillas, L. N. et al. 2008. Systemic activation of the transient receptor potential vanilloid subtype 4 channel causes endothelial failure and circulatory collapse: Part 2. J Pharmacol Exp Ther 326, 443-452.

Wolfle, S. E., Schmidt, V. J., Hoyer, J., Kohler, R. \& de, W. C. 2009. Prominent role of KCa3.1 in endothelium-derived hyperpolarizing factor-type dilations and conducted responses in the microcirculation in vivo. Cardiovasc Res 82, 476-483.

Xia, Y., Fu, Z., Hu, J., Huang, C., Paudel, O., Cai, S., Liedtke, W. \& Sham, J. S. 2013. TRPV4 channel contributes to serotonin-induced pulmonary vasoconstriction and the enhanced vascular reactivity in chronic hypoxic pulmonary hypertension. Am J Physiol Cell Physiol 305, C704-C715.

Yang, X. R., Lin, A. H., Hughes, J. M., Flavahan, N. A., Cao, Y. N., Liedtke, W. \& Sham, J. S. 2012. Upregulation of osmo-mechanosensitive TRPV4 channel facilitates chronic hypoxia-induced myogenic tone and pulmonary hypertension. Am J Physiol Lung Cell Mol Physiol 302, L555L568.

This article is protected by copyright. All rights reserved. 
Yin, J., Hoffmann, J., Kaestle, S. M., Neye, N., Wang, L., Baeurle, J., Liedtke, W., Wu, S., Kuppe, H., Pries, A. R. \& Kuebler, W. M. 2008. Negative-feedback loop attenuates hydrostatic lung edema via a cGMP-dependent regulation of transient receptor potential vanilloid 4. Circ Res 102, 966-974.

Yin, J., Michalick, L., Tang, C., Tabuchi, A., Goldenberg, N., Dan, Q., Awwad, K., Wang, L., Erfinanda, L., Nouailles, G., Witzenrath, M., Vogelzang, A., Lv, L., Lee, W. L., Zhang, H., Rotstein, O. et al. 2016. Role of Transient Receptor Potential Vanilloid 4 in Neutrophil Activation and Acute Lung Injury. Am J Respir Cell Mol Biol 54, 370-383.

Yoo, H. Y., Park, S. J., Seo, E. Y., Park, K. S., Han, J. A., Kim, K. S., Shin, D. H., Earm, Y. E., Zhang, Y. H. \& Kim, S. J. 2012. Role of thromboxane A(2)-activated nonselective cation channels in hypoxic pulmonary vasoconstriction of rat. Am J Physiol Cell Physiol 302, C307-C317.

Table 1. Characteristics of transient receptor potential vanilloid type 4 (TRPV4) and calcium-activated potassium channels with intermediate conductance (KCa3.1).

\begin{tabular}{|c|c|c|c|c|}
\hline & \multicolumn{2}{|c|}{ TRPV4 } & \multicolumn{2}{|r|}{ KCa3.1 } \\
\hline Conductance & $\begin{array}{l}30-60 \mathrm{pS} \text { at }-60 \\
\mathrm{mV}\end{array}$ & $\begin{array}{l}\mathrm{Ca}^{2+}>\mathrm{Mg}^{2+}>\mathrm{K}^{+}> \\
\mathrm{Cs}^{+}>\mathrm{Rb}^{+}>\mathrm{Na}^{+}>\mathrm{Li}^{+}\end{array}$ & $11-40 \mathrm{pS}$ & $\mathrm{K}^{+}>\mathrm{Rb}^{+}>\mathrm{NH}_{4}^{+}>\mathrm{Cs}^{+}$ \\
\hline Activators & $\begin{array}{l}4 \alpha \text { PDD } \\
\text { GSK1016790A } \\
\text { RN1747 }\end{array}$ & $\begin{array}{l}{ }^{*} \mathrm{EC}_{50}(\mu \mathrm{M}) \\
0.32 \\
0.002-0.02 \\
0.79\end{array}$ & $\begin{array}{l}\text { NS309 } \\
\text { SKA-121 } \\
\text { DC-EBIO }\end{array}$ & $\begin{array}{l}\mathrm{EC}_{50}(\mu \mathrm{M}) \\
0.01 \\
0.10 \\
4.1-4.5\end{array}$ \\
\hline Blockers & $\begin{array}{l}\text { HC067047 } \\
\text { GSK2193874 } \\
\text { RN1734 }\end{array}$ & $\begin{array}{l}\mathrm{EC}_{50}(\mu \mathrm{M}) \\
0.016-0.13 \\
0.002-0.02 \\
2.0-6.3\end{array}$ & $\begin{array}{l}\text { TRAM-34 } \\
\text { Charybdotoxin } \\
\text { Senicaproc }\end{array}$ & $\begin{array}{l}\mathrm{pEC}_{50}(\mu \mathrm{M}) \\
0.01-0.025 \\
0.002-0.025 \\
0.01\end{array}$ \\
\hline $\begin{array}{l}\text { Endogenous } \\
\text { activators }\end{array}$ & $\begin{array}{l}\text { EETs } \\
\text { NO mediated } \\
\text { S-nitrosylation }\end{array}$ & & $\begin{array}{l}\text { Intracellular } \\
\text { calcium }\end{array}$ & $\begin{array}{l}\mathrm{EC}_{50}(\mu \mathrm{M}) \\
0.1-0.79\end{array}$ \\
\hline
\end{tabular}

$\mathrm{EC}_{50}$, concentrations causing half maximal effect. *, range of $\mathrm{pEC}_{50}$ depends on species where the compounds have been tested. EETs, epoxyeicosatrienoic acid; $4 \alpha \mathrm{PDD}, 4 \alpha$-phorbol 12,13-didecanoate; NO, nitric oxide. Further details on the channels can be found on the following address: www.guidetopharmacology.org

This article is protected by copyright. All rights reserved. 


\section{Legends}

Figure 1. Structure and regulation of TRPV4 channel.

Figure 2. Scheme showing calcium influx through TRPV4 channels in endothelial cell (E) followed by activation of calcium-activated potassium channels (KCa2.3 and KCa3.1) and endothelial nitric oxide synthase (eNOS). The potassium released from the endothelial cells leads to increased $\mathrm{Na}^{+} / \mathrm{K}^{+}$-ATPase activation and smooth muscle hyperpolarization while NO stimulates soluble guanylyl cyclase (sGC), formation of cyclic GMP and opening of smooth muscle large conductance calcium-activated potassium channels (KCa1.1). The resulting hyperpolarization reduce calcium influx through voltage-gated Ltype calcium channels and relaxation of the underlying smooth muscle layer. Opening of the TRPV4 channels in the smooth muscle may occur during inhibition of eNOS activity.

\section{Figure 3. Hypothetical role of blood-alveolar lung KCa3.1 channels in oedema}

formation during involvement of TRPV4 channels. (A) The three conditions, increased pulmonary venous pressure due to acute left heart disease $(\Delta \mathrm{P})$, high inflation pressure, and chemically-induced lung injury leads to activation of transient receptor potential vanilloid type 4 channels (TRPV4). This activation produces permeability of the endothelial (E) cell layer and protein and liquid accumulation in the alveoles. (B) The scheme shows the mechanisms involved in the endothelial-alveolar barrier (alveolar epithelial type I (AEI) and type II (AEII) cells). Here calcium influx through TRPV4 channels activates calciumactivated potassium channels (KCa3.1) which in turn produce hyperpolarization and promotes in terms of a positive-feed-back loop additional calcium influx in endothelial cells and AEI and AEII. Moreover, the hyperpolarization provides the driving force for chloride efflux through $\mathrm{Ca}^{2+}$-activated $\mathrm{Cl}^{-}$channels $(\mathrm{CaCC})$ and cyclic AMP-regulated cystic fibrosis transmembrane regulator chloride channel (CFTR) causing extracellular liquid accumulation. The liquid clearance by sodium transport through the ENaC channel and the CFTR is reduced 
in both AEI and AEII cells. Water may diffuse paracellularly. Aquaporins in the endothelial/epithelium may be of less importance. White blood cells (WBC) including both macrophages and neutrophils may act as mediators of inflammatory responses and thereby contribute to the pathophysiological processes by further accelerating the endothelial dysfunction and barrier disruption. RBC, red blood cells.

\section{Figure 4. Lung parameters measured in wild type (wt) and KCa3.1 channel deficient}

(KCa3.1-/-) mice by use of forced oscillatory pressure. Respiratory system elastance (A) and tissue elastance (B) measured as changes in pressure achieved per unit change in volume or stiffness in mice 2 weeks after tracheal instillation of vehicle or the lung fibrosis-inducing drug, bleomycin. There were no differences comparing parameters in wild type and $\mathrm{KCa} 3.1^{-/-}$ . The results are means \pm s.e.m. of $8-10$ mice. ${ }^{*} \mathrm{P}<0.05$ versus control mice compared with $2-$ way analysis of variance. There was no interaction.

\section{Figure 5. Accumulation of extracellular liquid is inhibited in lungs from $\mathrm{KCa}^{-1 /-}$ mice.} GSK1016790A was infused and the wet weight was obtained, and expressed as ratio of the dried lung weight (W/D). The dry weight was obtained after the tissue has been dried in a microwave oven for four days. ${ }^{*} \mathrm{P}<0.05$ versus GSK1016790A-infused wild type mice $(\mathrm{n}=4)$.

This article is protected by copyright. All rights reserved. 


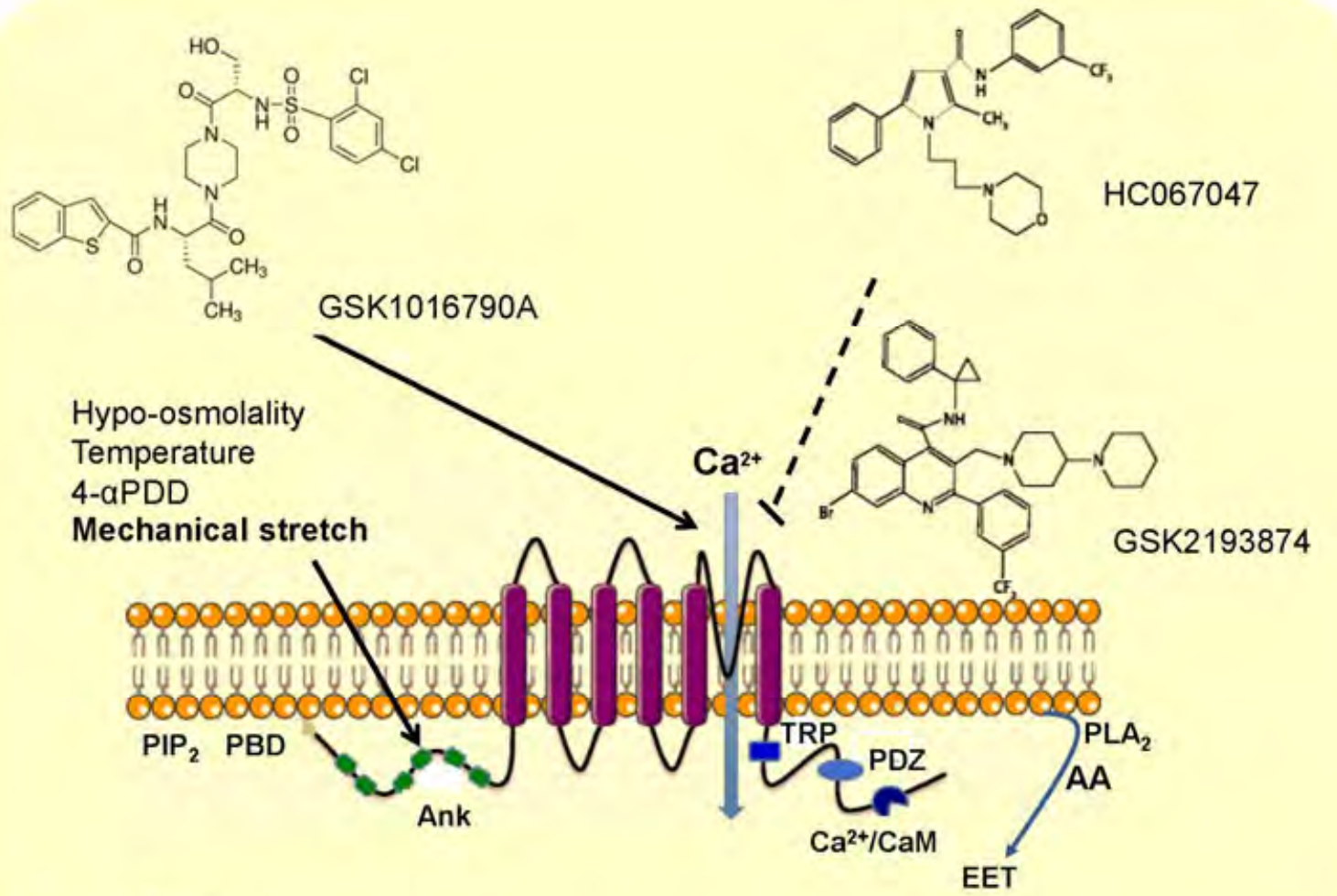

Figure 1

This article is protected by copyright. All rights reserved. 


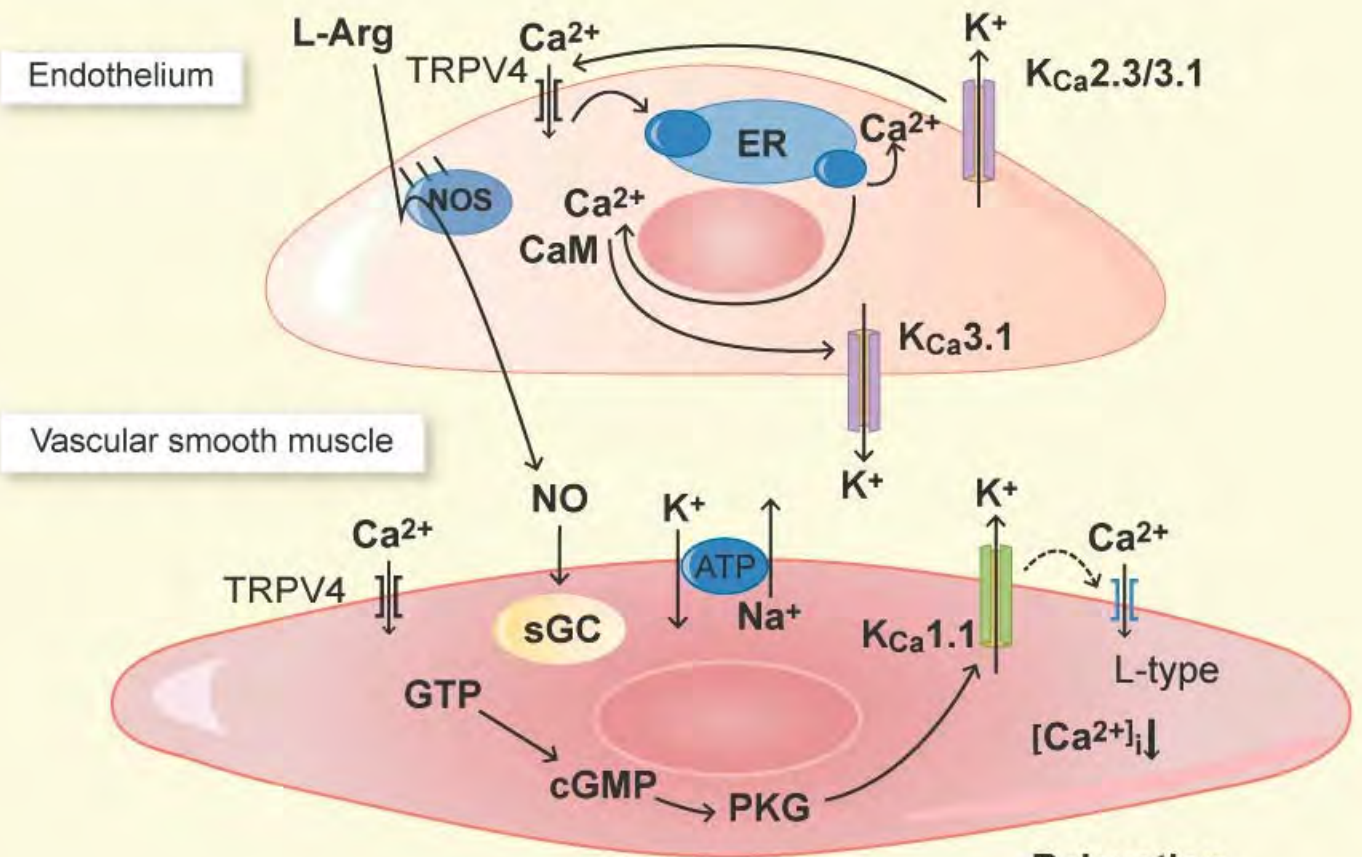

Relaxation

This article is protected by copyright. All rights reserved. 


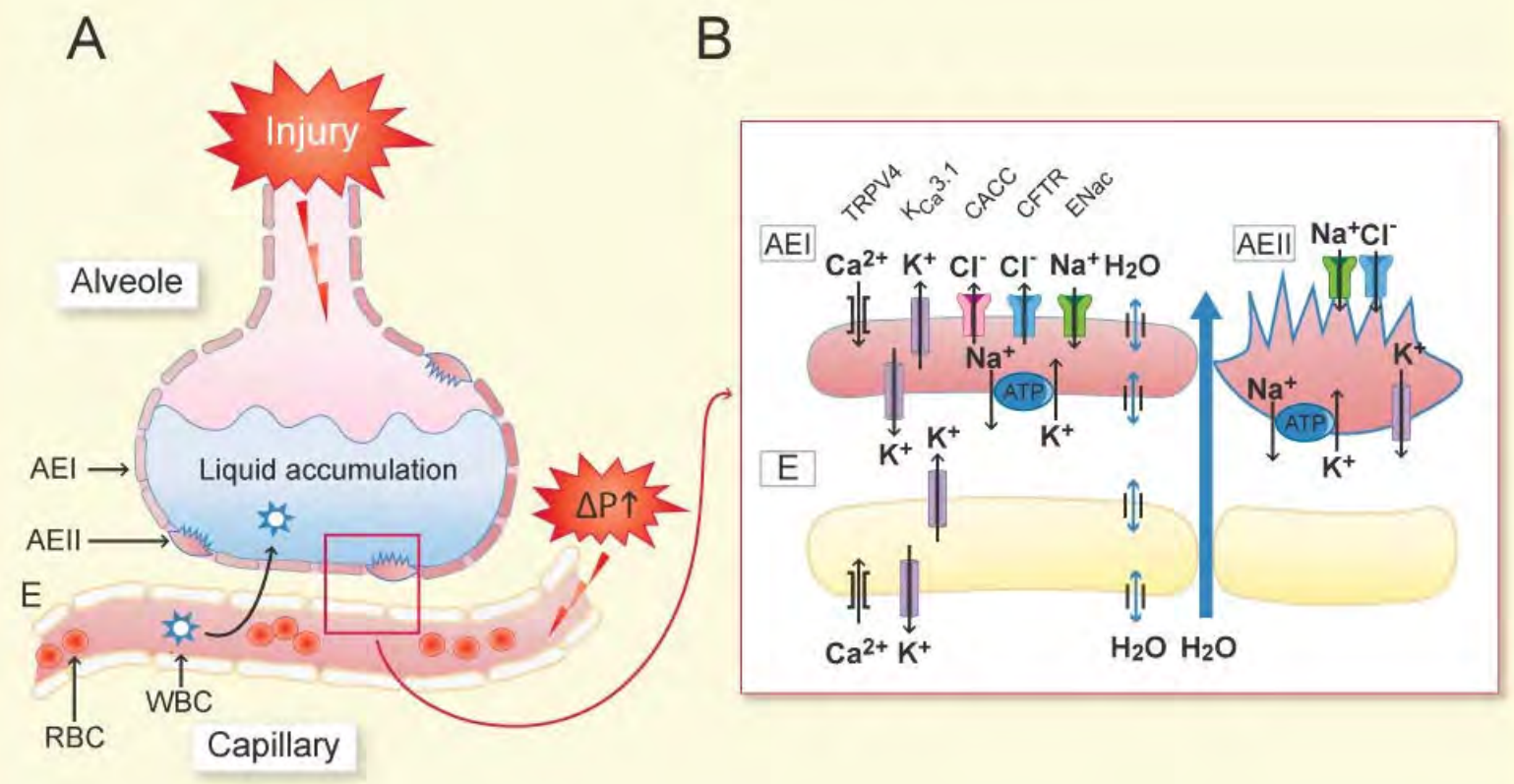

A
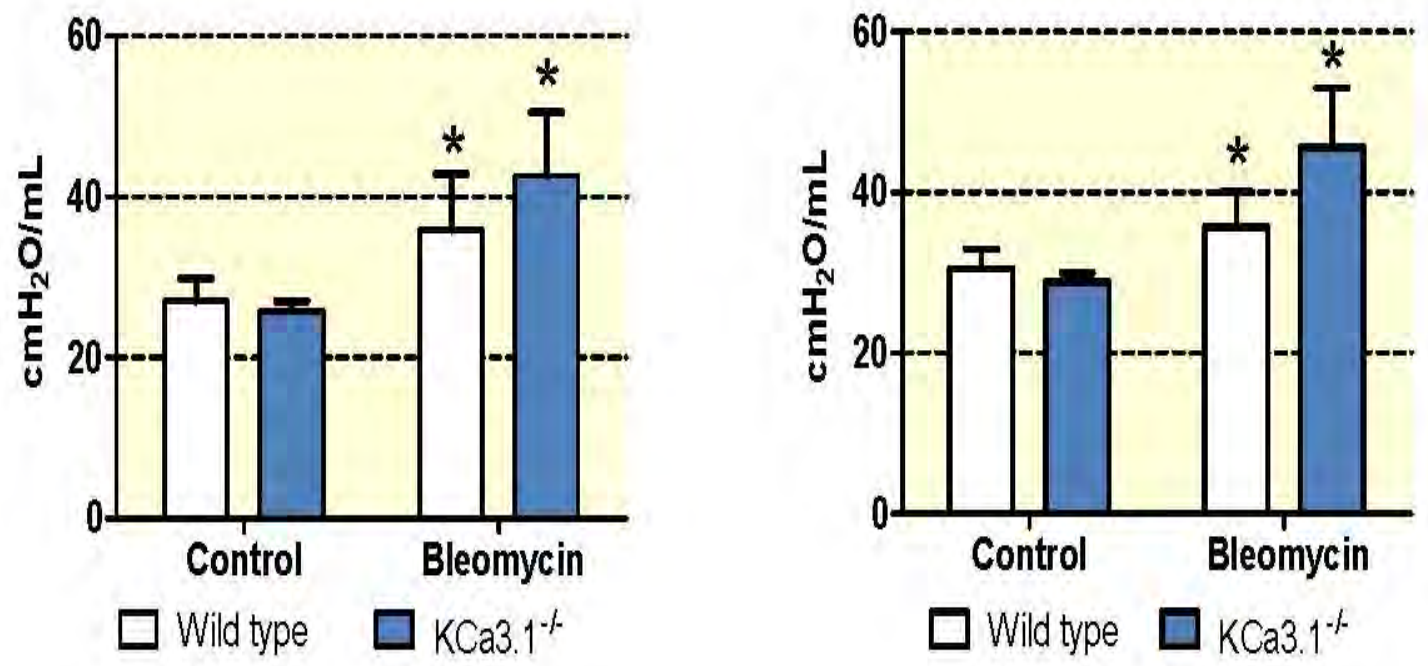

Figure 4 


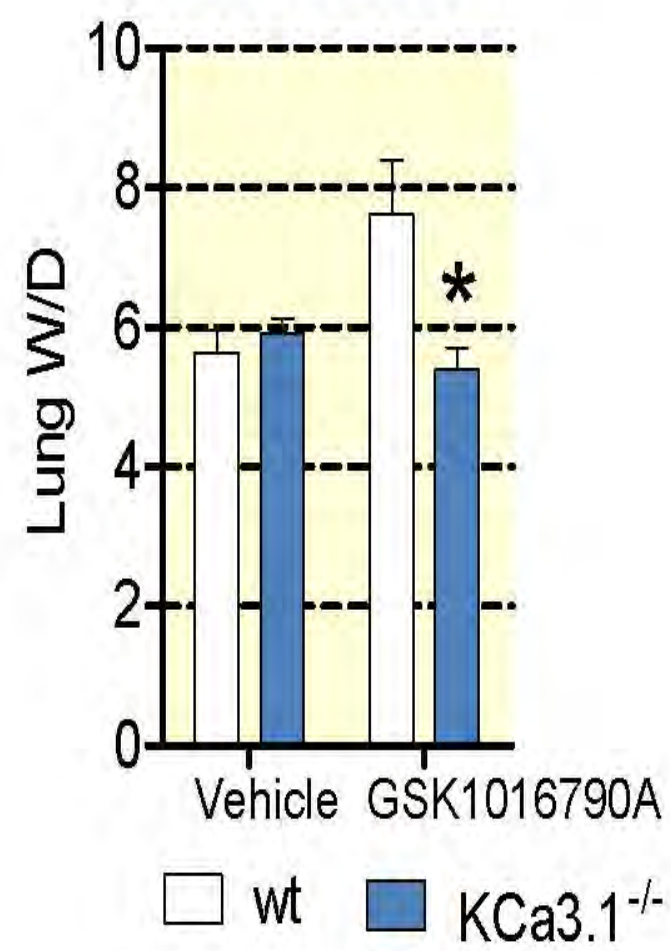

Figure 5 